This item was submitted to Loughborough's Research Repository by the author.

Items in Figshare are protected by copyright, with all rights reserved, unless otherwise indicated.

\title{
The effect of exercise training on intrahepatic triglyceride and hepatic insulin sensitivity: a systematic review and meta-analysis
}

\section{PLEASE CITE THE PUBLISHED VERSION}

https://doi.org/10.1111/obr.12719

\section{PUBLISHER}

Wiley (C) World Obesity Federation

\section{VERSION}

AM (Accepted Manuscript)

\section{PUBLISHER STATEMENT}

This is the peer reviewed version of the following article: SARGEANT, J.A. ...et al., 2018. The effect of exercise training on intrahepatic triglyceride and hepatic insulin sensitivity: a systematic review and metaanalysis. Obesity Reviews, 19 (10), pp.1446-1459, which has been published in final form at https://doi.org/10.1111/obr.12719. This article may be used for non-commercial purposes in accordance with Wiley Terms and Conditions for Use of Self-Archived Versions

\section{LICENCE}

CC BY-NC-ND 4.0

\section{REPOSITORY RECORD}

Sargeant, Jack, L.J. Gray, Danielle H. Bodicoat, Scott Willis, David Stensel, Myra A. Nimmo, Guruprasad P. Aithal, and James King. 2018. "The Effect of Exercise Training on Intrahepatic Triglyceride and Hepatic Insulin Sensitivity: A Systematic Review and Meta-analysis". Loughborough University. https://hdl.handle.net/2134/33175. 
The effect of exercise training on intrahepatic triglyceride and hepatic insulin sensitivity: a systematic review and meta-analysis

Jack A. Sargeant ${ }^{1,2}$, Laura J. Gray ${ }^{3}$, Danielle H. Bodicoat ${ }^{2,4}$, Scott A. Willis ${ }^{1,2}$, David J. Stensel $^{1,2}$, Myra A. Nimmo ${ }^{5}$, Guruprasad P. Aithal ${ }^{6,7}$, James A. King ${ }^{1,2}$.

${ }^{1}$ National Centre for Sport and Exercise Medicine, School of Sport, Exercise \& Health Sciences, Loughborough University, UK

${ }^{2}$ National Institute for Health Research (NIHR) Leicester Biomedical Research Centre, Leicester, UK

${ }^{3}$ Department of Health Sciences, University of Leicester, UK

${ }^{4}$ Diabetes Research Centre, University of Leicester, UK

${ }^{5}$ College of Life \& Environmental Sciences, University of Birmingham, UK

${ }^{6}$ Nottingham Digestive Diseases Centre, School of Medicine, University of Nottingham

${ }^{7}$ National Institute for Health Research (NIHR) Nottingham Biomedical Research Centre, Nottingham University Hospitals NHS Trust and University of Nottingham, UK

Keywords (3 to 4 max): physical activity; non-alcoholic fatty liver disease; type 2 diabetes mellitus; insulin resistance

Running title: Exercise, intrahepatic triglyceride \& hepatic insulin sensitivity

\section{Acknowledgements}

We would like to thank the authors of included studies who responded to data requests during data extraction and analysis. 


\section{Address for correspondence:}

Dr James King,

Lecturer in Exercise Physiology

School of Sport, Exercise and Health Sciences

Loughborough University

Leicestershire

United Kingdom

LE11 3TU

Phone: $+44(0) 1509228457$

Email: j.a.king@lboro.ac.uk

\section{Conflict of Interest Statement}

All authors have no conflicts of interest to declare in relation to this work. DHB is now employed by Walgreens Boots Alliance but was paid no money by them during the undertaking of this work. GPA has received payments for invited lectures by EASL, AASLD and APASL and has received travel and accommodation for attendance of conferences as a faculty member.

\section{List of Abbreviations (in order of mention in the paper):}

IHTG - intrahepatic triglyceride

NAFLD - non-alcoholic fatty liver disease

T2DM - type 2 diabetes mellitus

DAG - diacylglycerol

EGP - endogenous glucose production

US - ultrasound 
CT - computed tomography

${ }^{1} \mathrm{H}-\mathrm{MRS}$ - proton magnetic resonance spectroscopy

HISI - hepatic insulin sensitivity index

$\%$ EGP $_{\text {supp }}$ - percentage suppression of endogenous glucose production during low dose insulin infusion

$\mathrm{RCT}$ - randomised controlled trial

HIRI - hepatic insulin resistance index

FPI - fasted plasma insulin

$95 \% \mathrm{CI}-95 \%$ confidence interval

HIIT - high-intensity interval training 


\section{Abstract}

This systematic review and meta-analysis determined the impact of structured exercise training, and the influence of associated weight loss, on intrahepatic triglyceride (IHTG) in individuals with non-alcoholic fatty liver disease (NAFLD). It also examined its effect on hepatic insulin sensitivity in individuals with or at increased risk of NAFLD. Analyses were restricted to studies using magnetic resonance spectroscopy or liver biopsy for the measurement of IHTG and isotope-labelled glucose tracer for assessment of hepatic insulin sensitivity. Pooling data from 17 studies (373 exercising participants), exercise training for one to 24 weeks (mode: 12weeks) elicits an absolute reduction in IHTG of 3.31\% (95\% CI: 4.41 to $-2.22 \%)$. Exercise reduces IHTG independent of significant weight change (-2.16 [2.87 to -1.44$] \%)$, but benefits are substantially greater when weight loss occurs (-4.87 [-6.64 to -3.11$] \%)$. Furthermore, meta-regression identified a positive association between percentage weight loss and absolute reduction in IHTG ( $\beta=0.99$ [0.62 to 1.36], $P<0.001)$. Pooling of six studies (94 participants) suggests that exercise training also improves basal hepatic insulin sensitivity (mean change in hepatic insulin sensitivity index: 0.13 [0.05 to $0.21] \mathrm{mg} \cdot \mathrm{m}^{-2} \cdot \mathrm{min}^{-1}$ per $\left.\mu \mathrm{U} \cdot \mathrm{mL}^{-1}\right)$, but available evidence is limited and the impact of exercise on insulin-stimulated hepatic insulin sensitivity remains unclear. 


\section{Introduction}

Non-alcoholic fatty liver disease (NAFLD) is a leading cause of chronic liver disease worldwide (1) and a prominent risk factor for cardiovascular disease, chronic kidney disease and type 2 diabetes mellitus (T2DM) (2). Insulin resistance promotes hepatic lipid accumulation, which is most commonly assessed via the measurement of intrahepatic triglyceride (IHTG) (3-6). The associated accumulation of lipid intermediates, such as diacylglyerol (DAG), may in turn perpetuate insulin resistance (3-6); providing a mechanistic link between NAFLD and impaired metabolic regulation. As such, strong associations exist between excess IHTG and insulin resistance in multiple tissues, including the liver $(3,7,8)$. Defects in hepatic insulin signalling contribute to elevated endogenous glucose production (EGP) which is integral to the pathophysiology of impaired glucose regulation and T2DM $(6,9,10)$.

Prompted by reports that exercise training has the capacity to reduce IHTG in the absence of weight loss $(11,12)$, the independent effects of exercise in the treatment of NAFLD have been examined (13-17). These reviews confirm the ability of exercise to reduce IHTG without significant weight change; however, the importance of the exercise-related energy deficit and subsequent weight loss has not been investigated thoroughly. Acute and sustained energy restriction and weight loss potently reduces IHTG in individuals with NAFLD $(18,19)$ and therefore logic dictates that weight loss associated with exercise training would be an important mediator of the IHTG response to exercise training. This issue has practical implications for the prescription of exercise in the management of NAFLD and thus deserves explicit attention. 
Previous reviews highlight a range of different methods to estimate IHTG, including noninvasive imaging by ultrasound (US) or computed tomography (CT), proton magnetic resonance spectroscopy $\left({ }^{1} \mathrm{H}-\mathrm{MRS}\right)$ and invasive liver biopsy. The inclusion of multiple methods within these reviews has the benefit of broadening study eligibility and thus increasing pooled participant sample size. However, it also adds an additional source of heterogeneity. US and CT are also limited by a lack of sensitivity to detect mild-to-moderate accumulation of IHTG and to quantify subtle changes resulting from experimental interventions (20). ${ }^{1} \mathrm{H}$-MRS has much greater precision (21), making it a more suitable method for experimental research, whilst the necessity to characterise histological features beyond steatosis make liver biopsy the standard tool in clinical practice $(22,23)$.

The effect of exercise training on hepatic insulin sensitivity has not been reviewed. A number of indices exist which assess insulin resistance using simple circulating biomarkers (24) but stable or radioactive isotope-labelled tracers are required to obtain the most accurate measurement of insulin sensitivity in individual tissues (25). Glucose tracers can be used to quantify EGP (primarily attributed to hepatic glucose production) (10) to accurately assess hepatic insulin sensitivity in the basal (fasted) and insulin-stimulated (post-prandial) states; using the hepatic insulin sensitivity index (HISI) and percentage suppression of EGP (\% $\left.\mathrm{EGP}_{\text {supp }}\right)$ by low-dose insulin infusion, respectively $(24,26)$.

This systematic review and meta-analysis had two primary aims. First, we investigated the effects of structured exercise training on IHTG in individuals with NAFLD, with a particular focus on the impact of concurrent weight loss, whilst restricting analyses to studies using ${ }^{1} \mathrm{H}$ MRS and liver biopsy. Second, we explored the effects of exercise training on basal and insulin-stimulated hepatic insulin sensitivity. 


\section{Methods}

The current systematic review and meta-analysis (PROSPERO ID: CRD42014007268) was conducted in accordance with the "Cochrane handbook for systematic reviews of interventions" and PRISMA guidelines $(27,28)$. All aspects of the literature search, study selection and risk of bias assessment were completed by two researchers independently (JS and JK/SW). Data extraction and analysis were performed by a single researcher (JS) before being checked, independently, by another (extraction: JK; analysis: DB/LG).

\section{Primary outcomes}

This review had two outcome measures:

- $\quad$ IHTG

- Hepatic insulin sensitivity (basal and insulin-stimulated)

Eligible studies were restricted to those using ${ }^{1} \mathrm{H}-\mathrm{MRS}$ or liver biopsy for the measurement of IHTG, and using isotope-labelled glucose tracer to quantify EGP in the fasted state and following low-dose $\left(\leq 20 \mathrm{mU} \cdot \mathrm{m}^{-2} \cdot \mathrm{min}^{-1}\right.$ or $\left.\leq 0.5 \mathrm{mU} \cdot \mathrm{kg}^{-1} \cdot \mathrm{min}^{-1}\right)$ insulin infusion, for the calculation of $\mathrm{HISI}$ and $\% \mathrm{EGP}_{\text {supp}}$, respectively.

\section{Literature search}

Six electronic online databases (EMBASE, MEDLINE, PubMed, Scopus, Sport Discus and Web of Science) were searched from inception to July 2017 using terms related to exercise, IHTG and hepatic insulin sensitivity. The full list of search terms can be found in supplementary methods. Reference lists of all included manuscripts were screened for further eligible studies. 


\section{Study selection}

Human experimental studies written in the English language were included. Conference abstracts were considered but underwent the same eligibility and risk of bias assessments as full articles. Eligible studies were those in which participants with overweight or obesity completed an exercise training programme of at least three exercise sessions. All types of study design were considered. Studies investigating changes in IHTG were only eligible if participants had diagnosed NAFLD or where baseline characteristics met diagnostic criteria (IHTG $>5 \%$ in the absence of secondary steatogenic sources, including excessive alcohol intake and viral infection $(22,23))$. NAFLD was not an inclusion criterion for studies investigating changes in hepatic insulin sensitivity as it became apparent that very few studies have examined this outcome exclusively in this patient group and a number of otherwise eligible studies did not measure IHTG. Studies investigating exercise in combination with dietary intervention were eligible only when data were available for matched, independent groups prescribed exercise training with or without diet. In studies measuring hepatic insulin sensitivity, it was essential that participants refrained from strenuous exercise for at least 48 hours before assessments (29).

\section{Data extraction}

Descriptive information (first author and year of publication), details of study design, participant and intervention characteristics and outcome data were extracted from eligible manuscripts. Outcome data were extracted as mean change and standard deviation from preto post-intervention for all exercise groups, as well as for the control groups of randomised controlled trials (RCTs). Where possible, outcome data presented in alternative forms were converted as outlined in supplementary methods. When incomplete or insufficient data were reported, the authors were contacted. If the required data were unavailable the study was 
removed. When characteristics of exercise interventions (such as the frequency, intensity or duration of exercise sessions) progressed over the course of a programme, a weighted mean was calculated. Further details of data extraction can be found in supplementary methods.

A number of variations of HISI exist, including the statistical inverse (the hepatic insulin resistance index; HIRI). Studies reporting these alternatives were included in qualitative review but were only included in quantitative meta-analysis when raw data were available for the calculation of HISI as originally described (24):

$$
1000 /\left(\mathrm{EGP}\left[\mathrm{mg} \cdot \mathrm{m}^{-2} \cdot \mathrm{min}^{-1}\right] \mathrm{x} \text { fasted plasma insulin }\left[\mu \mathrm{U} \cdot \mathrm{mL}^{-1}\right]\right)
$$

Studies that reported EGP and fasted plasma insulin (FPI) separately were also considered, but were excluded from all analyses unless raw data were available for the calculation of HISI as above. Mean values of EGP and FPI were not combined. Similarly, when study design allowed the calculation of $\% \mathrm{EGP}_{\text {supp }}$ but it was not reported, raw data were requested.

\section{Risk of bias assessment}

Studies were assessed for risk of bias using a modified Downs and Black scale (30). This checklist includes 26 items divided into categories of (i) reporting, (ii) external validity, (iii) internal validity - bias, (iv) internal validity - confounding and (v) power. Modifications made to the original scale are outlined in supplementary methods. Consensus between the two independent assessors (JS/JK) was ensured. Publication bias was assessed using funnel plots. 
Pooled characteristics of study participants are presented as weighted means, accounting for differences in sample size, along with the range. Quantitative analysis was conducted using commercially available software (Stata IC, Version 14.1, StataCorp LP, Texas, USA). Pooled mean differences with $95 \%$ confidence intervals $(95 \% \mathrm{CI})$ were calculated for primary outcomes using random effects models and heterogeneity was assessed quantitatively using the $I^{2}$ statistic.

Where possible, primary outcomes were analysed in two ways:

Within-group analysis: The change from pre- to post-intervention measurements in all exercise groups of all eligible studies.

Between-group analysis: The difference in the change from pre- to post-intervention between exercise and control groups in RCTs only.

In RCTs with multiple exercise groups, groups were combined as outlined in supplementary methods. When groups were not suitable to be combined (for example, aerobic and resistance exercise training groups), data from the aerobic intervention group was used.

\section{Subgroup analyses and meta-regression}

Subgroup analyses were performed to investigate whether the presence of significant weight loss (defined as a statistically significant reduction in body weight from pre- to postintervention) explained heterogeneity in the response of IHTG to exercise training. The influence of the exercise mode (aerobic, high-intensity interval (HIIT), resistance or combined aerobic/HIIT-plus-resistance training) was also investigated, as was the exercise intensity (moderate- or high-intensity) of aerobic and HIIT interventions. Exercise intensity was categorised according to published criteria (31), which are summarised in Table 1. One 
study (32) prescribed exercise relative to maximal workload. This study was categorised using the same percentage categories as those of $\dot{V} \mathrm{O}_{2}$ peak. Meta-regression was also performed to explore the effects of intervention duration and the magnitude of body weight change on changes in IHTG. All subgroup analyses and meta-regressions were performed using the mean change from pre- to post-training in all exercise groups of eligible studies. Secondary analyses of hepatic insulin sensitivity were not performed due to the limited number of studies identified. 


\section{Results}

\section{Literature search}

Figure 1 presents a flowchart of the literature search and study selection processes. To summarise, 20,055 records were returned by the six online databases, along with five from reference lists of eligible manuscripts. Of these, 111 manuscripts underwent full assessment and 21 were eligible for inclusion (20 for meta-analyses). Twenty were complete articles and one was a conference abstract, although the latter has since been published in full (33). Table 2 presents an overview of eligible studies, but readers are directed to supplementary materials (Tables S1 to S3) for more detailed description.

\section{Insert Figure 1 here}

\section{Risk of bias assessment}

Full results of the risk of bias assessment can be found in supplementary materials (Table S4). Studies scored highly on items related to reporting, with the exception of reporting adverse events, and internal validity. Seven studies (11,18,34-38) blinded the investigators performing assessments of IHTG, but allocation concealment was only performed in three out of 10 RCTs $(34,37,38)$. Conversely, studies scored poorly in relation to external validity, primarily due to an inability to determine whether recruited participants were representative of the entire population or of those who were approached to participate. Funnel plots suggested minimal evidence of publication bias (Figure S1), although the plot of all intervention groups investigating IHTG suggested a small bias towards studies reporting small effects. This would, if anything, result in an attenuated pooled effect. Seven studies recorded energy intake using self-reported food diaries $(11,35,39-42)$ or a validated food frequency questionnaire (37). All of these reported no change in energy intake from pre- to 
post-intervention, although one (41) reported a small increase in carbohydrate intake in participants completing a high-intensity, low-volume exercise programme. One study (43) prescribed a weight maintenance diet to participants. A further 10 studies instructed participants to maintain their dietary habits throughout the duration of study involvement without formally monitoring diet $(18,33,34,38,44-49)$, whilst three manuscripts make no reference to the control of dietary intake $(12,32,36)$.

\section{The effects of exercise training on IHTG}

Eighteen studies reported the effects of exercise training on IHTG $(11,12,18,33-37,39-$ 42,44-48) (Table 2). Only one of these used paired liver biopsy (18), reporting no significant effect of 6-months resistance exercise on the percentage of hepatocytes affected by steatosis in individuals with NAFLD. The remaining 17 studies used ${ }^{1} \mathrm{H}-\mathrm{MRS}$ to measure IHTG so, to reduce heterogeneity, only these studies were included in subsequent meta-analyses. These studies contained 19 exercise groups and a combined total of 373 participants (male: 151 [40.5\%]; female: 182 [48.8\%]; data not reported: 40 [10.7\%]). Participants had a weighted mean age of 50 [range 15.5 to 60] years and were overweight or obese (body mass index: 30.6 [27.8 to 37.1$] \mathrm{kg} \cdot \mathrm{m}^{-2}$; body fat percentage: 35.6 [28.7 to 43.7$] \%$; waist circumference: 101.2 [95.2 to 111.9$] \mathrm{cm}$ ). Participants were reported as sedentary and/or inactive and had low aerobic capacity (peak oxygen uptake: 25.2 [21.8 to 38.7$] \mathrm{ml} \cdot \mathrm{kg}^{-1} \bullet \mathrm{min}^{-1}$ ). Two studies actively recruited individuals with T2DM (34) or dysregulated glucose metabolism (37), whilst the mean baseline characteristics of seven other studies $(11,36,38,39,46-48)$ met diagnostic criteria for impaired fasted glucose (weighted mean fasted glucose: 5.61 [4.09 to 6.80] $\left.\mathrm{mmol} \cdot \mathrm{L}^{-1}\right)(50)$. The weighted mean IHTG at baseline was 15.8 [6.9 to 23.1] $\%$. 
Interventions included aerobic $(\mathrm{n}=11)$, HIIT $(\mathrm{n}=3)$, resistance $(\mathrm{n}=2)$, combined aerobic/HIIT-plus-resistance $(n=2)$ and acceleration/vibration $(n=1)$ exercise training, ranging from seven days to 24 weeks (mode: 12 weeks). Session frequency ranged from two to seven times per week (mode: three times per week) for 30 to 60 minutes. Six aerobic interventions used moderate-intensity exercise whilst the remaining five, along with all of the HIIT interventions, were categorised as high-intensity.

Ten of the included studies were RCTs, containing a combined 283 and 169 participants in exercise and control groups, respectively (Table 2). Pooled participant and intervention characteristics of RCTs only can be found in supplementary materials (Tables S5 and S6). There were no significant differences between the pooled characteristics of RCTs and those of all eligible studies $(P \geq 0.13)$. Participants in RCT control groups were instructed to maintain standard care $(n=5)$ or habitual lifestyle activities $(n=1)$, prescribed a lowintensity stretching programme $(n=2)$ or attended sessions providing education on the health benefits of exercise $(n=2)$.

Fourteen of the 17 studies reported a statistically significant benefit of exercise on IHTG either within-group $(33,37,40,42,44)$, between-group $(11,12)$, or both $(34-36,38,41,47,48)$. In the two studies with multiple exercise groups, exercise elicited a significant reduction in both groups $(38,41)$. One RCT reported a significant reduction from baseline, but this was not significant when compared to the change in the control group (40). Of the three studies that reported no benefit of exercise, two were short interventions (performing exercise on seven consecutive days) $(39,46)$, whilst the other was a resistance exercise programme in obese adolescents (45). 
When data from pre- to post-exercise in all interventions were pooled, a statistically significant benefit of exercise training was found (Figure 2), but high heterogeneity was also apparent. In a sensitivity analysis of RCTs only, the significant benefit of exercise was strengthened (mean difference in change between groups [95\% CI]: $-3.61[-4.68$ to -2.54$] \%$; Figure S2), and results were highly homogeneous $\left(I^{2}<0.1 \%, P=0.84\right)$. Therefore, to allow the inclusion of maximum data, subgroup analyses and meta-regressions were performed using the within-group change in all interventions.

\section{Insert Figure 2 here}

Exercise training significantly reduced IHTG in the absence of weight loss. However, when significant weight loss occurred, the pooled effect was substantially greater (Figure 3). Furthermore, meta-regression displayed a significant positive relationship between the change in body weight (relative to baseline) and the absolute change in IHTG $(\beta=0.99[95 \%$ CI: 0.62 to 1.36$], P<0.001$; Figure S3). A significant relationship was also apparent between intervention duration and change in IHTG $(\beta=-0.27$ [95\% CI: -0.35 to -0.19 ], $P<$ 0.001; Figure S4), suggesting that as the duration of intervention increases, so does the magnitude of reduction in IHTG. The duration of interventions that elicited significant weight loss versus those that did not were similar (median [range]: 12 [8 to 24] vs. 12 [1 to 16] weeks), but bivariate Pearson's correlation analysis showed a significant positive relationship between the duration of intervention and magnitude of weight loss elicited $\left(r^{2}=36 \%, P<\right.$ 0.01).

\section{Insert Figure 3 here}


Figure 2 displays the mean change from baseline in IHTG for all interventions categorised by exercise type. The pooled effect on IHTG for aerobic exercise interventions was greater than that for each other mode of exercise, as well as the pooled mean for all interventions. However, the high prevalence of aerobic interventions in comparison to other types of intervention should be noted. When interventions were grouped according to exercise intensity, the pooled effect for moderate-intensity interventions was greater than that of the high-intensity exercise programmes $\left(-4.82[-7.00\right.$ to -2.65$] \%, I^{2}=75.5 \%, P=0.001$ vs. ($2.89[-4.25$ to -1.53$\left.] \%, I^{2}=73.2 \%, P<0.001\right)$. The intervention duration of the moderate and high-intensity interventions were similar (median [range]: 14 [4 to 24] vs. 12 [1 to 24] weeks).

Overview of studies investigating the effects of exercise on hepatic insulin sensitivity Eight studies, containing a total of 10 exercise groups, reported the effects of exercise training on hepatic insulin sensitivity $(18,32,33,35,43,45,49,51)$ (Table 2). Four studies reported HISI $(33,43-45)$, although three presented EGP (and thus HISI) in different units to those outlined above. Two studies reported HIRI $(18,35)$. Four studies were able to provide raw data for the re-calculation of HISI $(18,35,44,45)$, along with two that reported EGP and FPI separately $(32,49)$. As such, seven studies (eight exercise groups) were included in metaanalysis of changes in HISI with exercise training. Only two of these $(35,49)$ were RCTs with a non-intervention/standard care control group (containing a combined 22 and 14 participants in exercise and control groups, respectively) so only within-group analysis was conducted. Three studies also reported \%EGP supp with low-dose insulin infusion $(33,35,49)$ but, due to this limited number, meta-analysis was not performed. Seven further studies were found that utilised a study design allowing the calculation of at least one of HISI or \%EGP $\mathrm{Eupp}_{\text {, but }}$ 
neither were reported (52-58). Whilst the authors of five of these studies kindly replied to requests for raw data, none were able to provide it.

\section{The effects of exercise training on basal hepatic insulin sensitivity}

The study that was excluded from meta-analysis of changes in HISI reported a tendency for a reduction in HIRI in obese adolescent girls following 12 weeks of resistance exercise training, but not after 12 weeks of moderate- to high-intensity aerobic exercise (43). The remaining eight exercise groups were pooled and had a combined total of 105 participants (male: 84 (80\%); female: 20 (19\%); data not available: $1(1 \%)$ ). Participants had a weighted mean age of 43 [range 15.5 to 59] years and, as per study selection criteria, were overweight or obese (body mass index: 31.3 [27.6 to 35.3$] \mathrm{kg} \cdot \mathrm{m}^{-2}$; body fat percentage: 34.0 [25.5 to 40.8] \%). Participants were reported as sedentary and/or inactive and had low aerobic capacity (maximal or peak oxygen uptake: 24.7 [21.6 to 32.0] $\mathrm{ml} \cdot \mathrm{kg}^{-1} \cdot \mathrm{min}^{-1}$ ). Five studies (five exercise groups) were conducted in individuals with diagnosed NAFLD or in those with baseline characteristics that met diagnostic criteria as outlined above $(18,33,35,45,51)$. One study included separate groups of patients with impaired fasted glucose and T2DM (32) but, according to mean baseline characteristics, all other studies recruited individuals with normal fasted glycaemia (weighted mean fasted glucose for all studies was 5.36 [4.70 to 9.00] $\left.\mathrm{mmol} \cdot \mathrm{L}^{-1}\right)(50)$. The weighted mean HISI at baseline was 0.99 [0.58 to 2.09$] \mathrm{mg}^{\circ} \mathrm{m}^{-2} \cdot \mathrm{min}^{-1}$ per $\mu \mathrm{U} \cdot \mathrm{mL}^{-1}$.

Studies included aerobic $(n=3)$, HIIT $(n=1)$, resistance $(n=2)$ and combined $(n=2)$ exercise interventions for six $(n=2), 12(n=5)$ or $24(n=1)$ weeks. Participants exercised on two to four days per week with sessions ranging from 20 to 60 minutes. One aerobic intervention, and the aerobic component of the combined exercise programmes, utilised 
moderate-intensity exercise, whilst the remaining aerobic interventions and the HIIT intervention were categorised as high-intensity.

Two of the eight exercise groups displayed a statistically significant improvement in HISI with exercise, both of which were in adolescents $(45,51)$. One study reported a tendency for reduced HIRI after exercise training, but this effect was statistically significant when HISI was re-calculated as above. Neither RCT reported a significant difference between exercise and control groups $(35,49)$. However, when data were pooled, a statistically significant benefit of exercise was found (Figure 4). Based on the weighted mean HISI at baseline, this pooled effect represents a relative improvement of approximately 13\%. Two studies in obese adolescents reported a reduction in basal EGP after aerobic or resistance exercise training $(45,51)$, but EGP was unaffected in all other studies. In contrast, FPI was significantly reduced in five of the exercise groups $(32,33,35,51)$, whilst the mean reduction in another (18) approached statistical significance. One study (35) reported a statistically significant reduction in body weight from pre- to post-exercise training $(2.5 \%)$ but this was not associated with an improvement in HISI. Another study (18) reported a mean reduction in body weight of similar magnitude $(2.6 \%)$ which, although not statistically significant, was associated with a significant improvement in HISI.

\section{Insert Figure 4 here}

\section{The effects of exercise training on insulin-stimulated hepatic insulin sensitivity}

Participant and intervention characteristics for the three studies examining the effects of

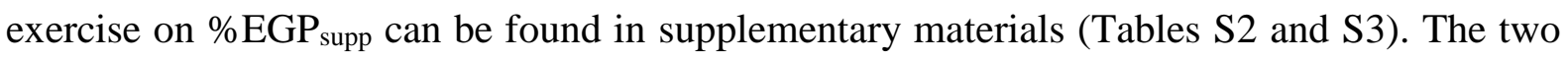
RCTs that reported HISI also reported \%EGP supp. One RCT reported a significant 
Page 19 of 43

improvement in $\% \mathrm{EGP}_{\text {supp }}$, compared to the control group, after six weeks of aerobic exercise training, despite no change in total body weight or IHTG (49). In contrast, \% EGP supp was reportedly unaffected by either twelve weeks of aerobic training (35) or six weeks of HIIT (33). 


\section{Discussion}

The prominent findings of this review are that structured exercise training, independent of dietary intervention, reduces IHTG in individuals with NAFLD. Importantly, whilst this effect is apparent without weight loss, the magnitude of reduction increases in direct proportion to the amount of weight loss induced by the intervention. Furthermore, our analyses indicate that exercise training for six to 24 weeks may also improve basal hepatic insulin sensitivity by approximately $13 \%$.

Previous reviews report that exercise training significantly reduces IHTG with a moderate to large pooled effect size $(13,15,17)$. The restriction of the current meta-analysis to a single technique $\left({ }^{1} \mathrm{H}-\mathrm{MRS}\right)$ allowed us to report this pooled effect as the absolute mean difference and our findings suggest that exercise training for between one and 24 weeks (mode 12 weeks) elicits an absolute reduction in IHTG of approximately 2.2 to $4.7 \%$ (mean $~ 3.5 \%$ ); reenforcing the meaningful therapeutic role of exercise for individuals with NAFLD. An important finding to emerge from this meta-analysis is the impact of weight loss as a mediator of the reduction in IHTG associated with exercise training interventions. This outcome is consistent with previous reviews $(59,60)$, which have highlighted the more potent impact of weight loss per se (primarily through dietary energy restriction) than the independent effect of exercise in the absence of body weight reduction. Specifically, our data show that whilst IHTG is significantly reduced in the absence of exercise-induced weight loss, the magnitude of effect is more than two-fold greater when weight loss occurs (-2.16 vs. 4.87\%). Meta-regression suggests that each $1 \%$ relative reduction in body weight is associated with approximately $1 \%$ absolute reduction in IHTG. Interestingly, an almost identical relationship can be seen in studies that have examined IHTG responses to short-, medium- and long-term dietary energy restriction interventions (61-63). These data therefore 
illustrate that relative changes in IHTG are several-fold greater than associated alterations in body weight regardless of physiological stimulus. This overriding influence of weight loss may also explain why previous reviews have not found additive benefits of exercise when combined with dietary intervention $(13,14)$. In these scenarios, large energy deficits created by dietary modification may dilute the much smaller contribution of exercise (64). Consequently, whilst exercise alone may be effective at reducing IHTG, the greatest therapeutic benefits will be realised when exercise interventions contribute to weight loss in combination with dietary energy restriction.

These findings have direct implications for exercise prescription in NAFLD. Specifically, the greatest impact of exercise training on IHTG is likely to occur with exercise that is associated with the greatest weight loss (14). Evidence suggests that aerobic exercise interventions typically evoke a higher amount of weight loss than anaerobic exercise modalities (65). The superiority of aerobic exercise interventions for reducing IHTG in individuals with NAFLD is supported by the present results and those of a previous meta-analysis (15). Consequently, although resistance exercise training and HIIT promote a reduction in IHTG in patients with NAFLD, greater benefits will likely be achieved through continuous aerobic exercise protocols such as running, swimming and cycling.

Exercise volume may also be an important variable which helps to explain why our analyses documented a larger reduction in IHTG with moderate- compared to high-intensity exercise interventions. Specifically, compared with shorter intense bouts of exercise, continuous moderate-intensity protocols commonly exhibit a greater total exercise volume and, consequently, energy expenditure. This higher level of energy expenditure may elicit a greater impact on metabolism, energy balance and IHTG. It is, however, important to 
consider that exercise-related energy expenditure may not necessarily translate into greater total daily energy expenditure $(66,67)$. Furthermore, given the inability to accurately calculate exercise-related energy expenditure in our review, further research is needed to investigate the precise relationship between exercise-related energy expenditure and IHTG.

Our analyses also demonstrate a significant relationship between the duration of exercise interventions and the change in IHTG, and a positive relationship between the duration of exercise training and the magnitude of weight loss. Each week of exercise training is associated with a reduction in IHTG of approximately $0.27 \%$. Collectively, our findings highlight the importance of developing sustainable exercise interventions, which, in combination with dietary strategies, may elicit the greatest benefits on IHTG in individuals with NAFLD.

The second part of this review examined the influence of exercise training on hepatic insulin sensitivity. Hepatic insulin resistance, which is strongly correlated with elevated IHTG $(3,7,8)$, contributes to impaired glycaemic control in the pathogenesis of T2DM $(6,9,10)$. We assessed the impact of exercise interventions on HISI and \%EGP supp, which are measures of hepatic insulin sensitivity in the basal and insulin-stimulated states, respectively. The paucity of studies examining these effects meant that our analyses were conducted using any study that recruited individuals with overweight or obesity, who are thus at increased risk of NAFLD, in addition to studies exclusively in patients with NAFLD.

In total, we identified eight studies (two of which had two exercise groups) which assessed the impact of exercise on basal hepatic insulin sensitivity $(18,32,33,35,43,45,49,51)$. Seven studies had sufficient data for inclusion in our meta-analysis but only two of which were 
RCTs. Therefore, our analysis was restricted to within-group changes in eight exercise groups. Interestingly, despite only three exercise groups displaying significant improvements in HISI from pre- to post- intervention $(18,45,51)$, our pooled analysis identified a statistically significant increase of approximately $13 \%$. In adults, basal rates of EGP were unaffected by exercise, but this improvement in basal hepatic insulin sensitivity may be reflected by a reduction of FPI. The clinical relevance of this magnitude of improvement in basal hepatic insulin sensitivity for individuals that are overweight and obese is not immediately clear. However, this novel finding suggests that exercise training favourably modifies this important parameter in individuals at risk of NAFLD and T2DM.

Three studies reported the effects of exercise on $\% \mathrm{EGP}_{\text {supp }}(33,35,49)$, two of which were RCTs employing aerobic exercise interventions of six and 12 weeks $(35,49)$. While one study reported significant improvement in $\% \mathrm{EGP}_{\text {supp}}$, no change was reported in the other. Therefore, we cannot draw firm conclusions on the impact of exercise training on insulinstimulated hepatic insulin sensitivity at this time.

It is notable that we identified a further seven studies whose methods permitted the

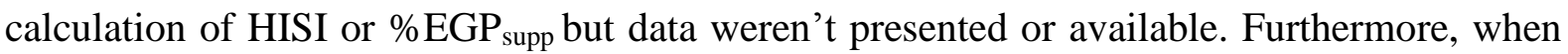
hepatic insulin sensitivity was reported, the precise details of the experimental methods employed, units used for presentation of outcomes and calculation of indices of hepatic insulin sensitivity, varied between studies. This review, therefore, highlights the need for greater methodological and reporting consistency when assessing hepatic insulin resistance (e.g. standardisation of low-dose insulin infusion when undertaking dual-stepped hyperinsulinaemic-euglycaemic clamps and consistent use of units). 
Our meta-analysis of the effects of exercise training on IHTG in individuals with NAFLD, and the mediating influence of weight loss, is the most precise quantitative synthesis to date. Furthermore, this is the first systematic review and meta-analysis assessing the impact of exercise interventions on hepatic insulin sensitivity. However, a few important considerations are noteworthy. A range of exercise interventions are identified and our analyses of the effects of exercise on IHTG display significant heterogeneity. Whilst we explore potential sources of this heterogeneity, it is assumed that these studies are suitable for data pooling. Secondly, although most included studies attempt to control habitual diet, this is notoriously difficult (68) and the potential for dietary changes to influence study outcomes must, therefore, be recognised. Additionally, our subgroup analyses investigating the influence of weight loss on IHTG were performed with studies categorised according to statistical, rather than clinical, significance. This has the potential to exclude studies from the weight loss group that demonstrate physiologically relevant, but not statistically significant, weight loss. Notably, however, this is unlikely in our analyses because, in the 'no weight loss' studies, the largest mean relative reduction in body weight after exercise training was $1.2 \%$. Furthermore, it assumed that weight loss resulting from exercise training is primarily reflective of a reduction in fat mass but some exercise regimens may promote the synthesis of skeletal muscle; attenuating any reduction in total body weight. It should also be noted that while a reduction in IHTG may be indicative of improved metabolic heath, these may be mediated by a reduction in hepatic lipid intermediates rather that IHTG per se (3-5). Finally, the limited number of studies investigating hepatic insulin sensitivity means that our findings should be taken with caution. Large RCTs are required to further investigate the effects of exercise training on hepatic insulin sensitivity, particularly in individuals with NAFLD and T2DM. 
In conclusion, this systematic review and meta-analysis has shown that exercise training reduces IHTG in individuals with NAFLD and, whilst benefits can be realised in the absence of weight loss, reductions in IHTG are proportionally related to the magnitude of weight loss induced. Furthermore, exercise training may improve basal hepatic insulin sensitivity in individuals that are overweight or obese, which may have beneficial implications for the management of NAFLD and T2DM. 


\section{Bibliography}

1. Younossi ZM, Koenig AB, Abdelatif D, Fazel Y, Henry L, Wymer M. Global epidemiology of non-alcoholic fatty liver disease - meta-analytic assessment of prevalence, incidence and outcomes. Hepatology 2016; 64: 73-84.

2. Byrne CD, Targher G. NAFLD: A multisystem disease. J Hepatol 2015; 62: S47-S64.

3. Shulman GI. Ectopic Fat in Insulin Resistance, Dyslipidemia, and Cardiometabolic Disease. N Engl J Med 2014; 371: 1131-1141.

4. Samuel VT, Liu ZX, Qu X, et al. Mechanism of hepatic insulin resistance in nonalcoholic fatty liver disease. J Biol Chem 2004; 279: 32345-32353.

5. Kumashiro N, Erion DM, Zhang D, et al. Cellular mechanism of insulin resistance in nonalcoholic fatty liver disease. Proc Natl Acad Sci USA 2011; 108: 16381-16385.

6. Taylor R. Pathogenesis of type 2 diabetes: Tracing the reverse route from cure to cause. Diabetologia 2008; 51: 1781-1789.

7. Korenblat KM, Fabbrini E, Mohammed BS, Klein S. Liver, muscle, and adipose tissue insulin action is directly related to intrahepatic triglyceride content in obese subjects. Gastroenterology 2008; 134: 1369-1375.

8. Bril F, Barb D, Portillo-Sanchez P, et al. Metabolic and histological implications of intrahepatic triglyceride content in nonalcoholic fatty liver disease. Hepatology 2017; 65: $1132-1144$.

9. Rizza RA. Pathogenesis of fasting and postprandial hyperglycemia in type 2 diabetes: Implications for therapy. Diabetes 2010; 59: 2697-2707.

10. Petersen MC, Vatner DF, Shulman GI. Regulation of hepatic glucose metabolism in health and disease. Nat Rev Endocrinol 2017; 13: 572-587.

11. Johnson NA, Sachinwalla T, Walton DW, et al. Aerobic exercise training reduces hepatic and visceral lipids in obese individuals without weight loss. Hepatology 2009; 
50: $1105-1112$.

12. Sullivan S, Kirk EP, Mittendorfer B, Patterson BW, Klein S. Randomized trial of exercise effect on intrahepatic triglyceride content and lipid kinetics in nonalcoholic fatty liver disease. Hepatology 2012; 55: 1738-1745.

13. Keating SE, Hackett DA, George J, Johnson NA. Exercise and non-alcoholic fatty liver disease: a systematic review and meta-analysis. J Hepatol 2012; 57: 157-166.

14. Smart NA, King N, McFarlane JR, Graham PL, Dieberg G. Effect of exercise training on liver function in adults who are overweight or exhibit fatty liver disease: a systematic review and meta-analysis. Br J Sports Med 2016; 1-11.

15. Orci LA, Gariani K, Oldani G, Delaune V, Morel P, Toso C. Exercise-based Interventions for Nonalcoholic Fatty Liver Disease: A Meta-analysis and Metaregression. Clin Gastroenterol Hepatol 2016; 14: 1398-1411.

16. Hashida R, Kawaguchi T, Bekki M, et al. Aerobic versus Resistance Exercise in Nonalcoholic Fatty Liver Disease: A Systematic Review. J Hepatol 2017; 66: 142-152.

17. Katsagoni CN, Georgoulis M, Papatheodoridis G V., Panagiotakos DB, Kontogianni MD. Effects of lifestyle interventions on clinical characteristics of patients with nonalcoholic fatty liver disease: A meta-analysis. Metabolism 2017; 68: 119-132.

18. Hickman IJ, Byrne NM, Croci I, et al. A Pilot Randomised Study of the Metabolic and Histological Effects of Exercise in Non-alcoholic Steatohepatitis. J Diabetes Metab 2013; 4: 300 .

19. Kirk E, Reeds DN, Finck BN, et al. Dietary fat and carbohydrates differentially alter insulin sensitivity during caloric restriction. Gastroenterology 2009; 136: 1552-1560.

20. Festi D, Schiumerini R, Marzi L, et al. The diagnosis of non-alcoholic fatty liver disease - availability and accuracy of non-invasive methods. Aliment Pharmacol Ther 2013; 37: 392-400. 
21. Bawden SJ, Scott R, Aithal GP. Current and future magnetic resonance technologies for assessing liver disease in clinical and experimental medicine. Dig Dis 2017; 35: $314-322$.

22. Chalasani N, Younossi Z, Lavine JE, et al. The Diagnosis and Management of Nonalcoholic Fatty Liver Disease: Practice Guidance from the American Association for the Study of Liver Diseases. Hepatology 2018; 67: 328-357.

23. EASL-EASD-EASO Clinical Practice Guidelines for the management of nonalcoholic fatty liver disease. J Hepatol 2016; 64: 1388-1402.

24. Matsuda M, DeFronzo RA. Insulin sensitivity indices obtained from oral glucose tolerance testing: Comparison with the euglycemic insulin clamp. Diabetes Care 1999; 22: $1462-1470$.

25. Kim I-Y, Suh S-H, Lee I-K, Wolfe RR. Applications of stable, nonradioactive isotope tracers in in vivo human metabolic research. Exp Mol Med 2016; 48: e203.

26. DeFronzo RA, Simonson D, Ferrannini E. Hepatic and peripheral insulin resistance: A common feature of Type 2 (non-insulin-dependent) and Type 1 (insulin-dependent) diabetes mellitus. Diabetologia 1982; 23: 313-319.

27. Moher D, Liberati A, Tetzlaff J, Altman DG. Preferred Reporting Items for Systematic Reviews and Meta-Analyses: The PRISMA Statement. Ann Intern Med 2009; 151: 264-269.

28. Higgins J, Green S. Cochrance Handbook for Systematic Reviews of Interventions. Chichester: John Wiley \& Sons Ltd.; 2011.

29. Sylow L, Kleinert M, Richter EA, Jensen TE. Exercise-stimulated glucose uptake regulation and implications for glycaemic control. Nat Rev Endocrinol 2017; 13: 133148.

30. Downs SH, Black N. The feasibility of creating a checklist for the assessment of the 
methodological quality both of randomised and non-randomised studies of health care interventions. J Epidemiol Community Heal 1998; 52: 377-384.

31. Garber CE, Blissmer B, Deschenes MR, et al. American College of Sports Medicine position stand. Quantity and quality of exercise for developing and maintaining cardiorespiratory, musculoskeletal, and neuromotor fitness in apparently healthy adults: guidance for prescribing exercise. Med Sci Sports Exerc 2011; 43: 1334-1359.

32. Meex RCR, Schrauwen-Hinderling VB, Moonen-Kornips E, et al. Restoration of muscle mitochondrial function and metabolic flexibility in type 2 diabetes by exercise training is paralleled by increased myocellular fat storage and improved insulin sensitivity. Diabetes 2010; 59: 572-579.

33. Sargeant JA, Bawden S, Aithal GP, et al. Effects of sprint interval training on ectopic lipids and tissue-specific insulin sensitivity in men with non-alcoholic fatty liver disease. Eur J Appl Physiol 2018; 118: 817-828.

34. Cassidy S, Thoma C, Hallsworth K, et al. High intensity intermittent exercise improves cardiac structure and function and reduces liver fat in patients with type 2 diabetes: a randomised controlled trial. Diabetologia 2016; 59: 56-66.

35. Cuthbertson DJ, Shojaee-Moradie F, Sprung VS, et al. Dissociation between exerciseinduced reduction in liver fat and changes in hepatic and peripheral glucose homoeostasis in obese patients with non-alcoholic fatty liver disease. Clin Sci 2016; 130: $93-104$.

36. Hallsworth K, Fattakhova G, Hollingsworth KG, et al. Resistance exercise reduces liver fat and its mediators in non-alcoholic fatty liver disease independent of weight loss. Gut 2011; 60: 1278-1283.

37. Langleite TM, Jensen J, Norheim F, et al. Insulin sensitivity, body composition and adipose depots following $12 \mathrm{w}$ combined endurance and strength training in 
dysglycemic and normoglycemic sedentary men. Arch Physiol Biochem 2016; 122: 167-179.

38. Zhang H-J, He J, Pan L-L, et al. Effects of moderate and vigorous exercise on nonalcoholic fatty liver disease. JAMA Intern Med 2016; 176: 1079-1082.

39. Haus JM, Solomon TPJ, Kelly KR, et al. Improved hepatic lipid composition following short-term exercise in nonalcoholic Fatty liver disease. J Clin Endocrinol Metab 2013; 98: E1181-1188.

40. Pugh CJA, Sprung VS, Kemp GJ, et al. Exercise training reverses endothelial dysfunction in nonalcoholic fatty liver disease. AJP Hear Circ Physiol 2014; 307: H1298-H1306.

41. Keating SE, Hackett DA, Parker HM, et al. Effect of aerobic exercise training dose on liver fat and visceral adiposity. J Hepatol 2015; 63: 174-182.

42. Oh S, Shida T, Sawai A, et al. Acceleration training for managing nonalcoholic fatty liver disease: a pilot study. Ther Clin Risk Manag 2014; 10: 925-936.

43. Lee S, Deldin AR, White D, et al. Aerobic exercise but not resistance exercise reduces intrahepatic lipid content and visceral fat and improves insulin sensitivity in obese adolescent girls: a randomized controlled trial. Am J Physiol Endocrinol Metab 2013; 305: E1222-1229.

44. van der Heijden G-J, Wang Z, Chu Z, et al. A 12-week aerobic exercise program reduces hepatic fat accumulation and insulin resistance in obese, Hispanic adolescents. Obesity 2010; 18: 384-390.

45. van der Heijden G-J, Wang Z, Chu Z, et al. Strength exercise improves muscle mass and hepatic insulin sensitivity in obese youth. Med Sci Sports Exerc 2010; 42: 19731980.

46. Malin SK, Mulya A, Fealy CE, et al. Fetuin-A is linked to improved glucose tolerance 
after short-term exercise training in nonalcoholic fatty liver disease. $J$ Appl Physiol 2013; 115: 988-994.

47. Hallsworth K, Thoma C, Hollingsworth KG, et al. Modified high-intensity interval training reduces liver fat and improves cardiac function in non-alcoholic fatty liver disease: a randomized controlled trial. Clin Sci 2015; 129: 1097-1105.

48. Houghton D, Thoma C, Hallsworth $\mathrm{K}$, et al. Exercise reduces liver lipids and visceral adiposity in patients with non-alcoholic steatohepatitis in a randomized controlled trial. Clin Gastroenterol Hepatol 2017; 15: 96-102.

49. Shojaee-Moradie F, Baynes KCR, Pentecost C, et al. Exercise training reduces fatty acid availability and improves the insulin sensitivity of glucose metabolism. Diabetologia 2007; 50: 404-413.

50. American Diabetes Association. Classification and Diagnosis of Diabetes: Standards of Medical Care in Diabetes-2018. Diabetes Care 2018; 41: S13-S27.

51. van der Heijden G-J, Toffolo G, Manesso E, Sauer PJJ, Sunehag AL. Aerobic exercise increases peripheral and hepatic insulin sensitivity in sedentary adolescents. $J$ Clin Endocrinol Metab 2009; 94: 4292-4299.

52. Coker RH, Hays NP, Williams RH, et al. Exercise-induced changes in insulin action and glycogen metabolism in elderly adults. Med Sci Sports Exerc 2006; 38: 433-438.

53. Coker RH, Williams RH, Yeo SE, et al. The impact of exercise training compared to caloric restriction on hepatic and peripheral insulin resistance in obesity. $J$ Clin Endocrinol Metab 2009; 94: 4258-4266.

54. DeFronzo RA, Sherwin R, Kraemer N. The effect of physical training on insulin action in obesity. Diabetes 1987; 36: 1379-1385.

55. DiPietro L, Dziura J, Yeckel CW, Neufer PD. Exercise and improved insulin sensitivity in older women: evidence of the enduring benefits of higher intensity 
training. J Appl Physiol 2006; 100: 142-149.

56. Hughes VA, Fiatarone MA, Fielding RA, et al. Exercise increases muscle GLUT-4 levels and insulin action in subjects with impaired glucose tolerance. Am J Physiol 1993; 264: E855-E862.

57. Kirk E, Sullivan S, Klein S. Exercise reduces intrahepatic triglyceride and improves insulin action in adults with nonalcoholic fatty liver disease. Med Sci Sport Exerc 2010; 42: 44 .

58. Segal KR, Edano A, Abalos A, et al. Effect of exercise training on insulin sensitivity and glucose metabolism in lean, obese, and diabetic men. J Appl Physiol 1991; 71: $2402-2411$.

59. Brouwers B, Hesselink MKC, Schrauwen P, Schrauwen-Hinderling VB. Effects of exercise training on intrahepatic lipid content in humans. Diabetologia 2016; 59: 2068-2079.

60. Golabi P, Locklear CT, Austin P, et al. Effectiveness of exercise in hepatic fat mobilization in nonalcoholic fatty liver disease: Systematic review. World $J$ Gastroenterol 2016; 22: 6318-6327.

61. Wong VW-S, Chan RS-M, Wong GL-H, et al. Community-based lifestyle modification programme for non-alcoholic fatty liver disease: a randomized controlled trial. J Hepatol 2013; 59: 536-42.

62. Browning JD, Baker JA, Rogers T, Davis J, Satapati S, Burgess SC. Short-term weight loss and hepatic triglyceride reduction: Evidence of a metabolic advantage with dietary carbohydrate restriction. Am J Clin Nutr 2011; 93: 1048-1052.

63. Patel NS, Doycheva I, Peterson MR, et al. Effect of weight loss on magnetic resonance imaging estimation of liver fat and volume in patients with nonalcoholic steatohepatitis. Clin Gastroenterol Hepatol 2015; 13: 561-568. 
64. Ross R, Freeman JA, Janssen I. Exercise alone is an effective strategy for reducing obesity and related comorbidities. Exerc Sport Sci Rev 2000; 28: 165-170.

65. Yumuk V, Tsigos C, Fried M, et al. European Guidelines for Obesity Management in Adults. Obes Facts 2015; 8: 402-424.

66. Pontzer H, Durazo-Arvizu R, Dugas LR, et al. Constrained total energy expenditure and metabolic adaptation to physical activity in adult humans. Curr Biol 2016; 26: $410-417$.

67. Melanson EL. The effect of exercise on non-exercise physical activity and sedentary behavior in adults. Obes Rev 2017; 18: 40-49.

68. Dhurandhar NV, Schoeller D, Brown AW, et al. Energy balance measurement: when something is not better than nothing. Int J Obes 2015; 39: 1109-1113.

69. Borg G. Percieved exertion as an indicator of somatic stress. Scand J Rehab Med 1970; 2: $92-98$. 
Page 34 of $\mathbf{4 3}$

Table 1 - Categories of exercise intensity

\begin{tabular}{|l|c|c|c|c|}
\hline & RPE & \% HR max & \% HRR & \% $\dot{\text { VO }}$ 2 peak \\
\hline Moderate-intensity & $12-13$ & $64-76$ & $40-59$ & $46-63$ \\
\hline High-intensity & $14-17$ & $77-95$ & $60-89$ & $64-90$ \\
\hline
\end{tabular}


Table 2 - Overview of included studies

\begin{tabular}{|c|c|c|c|c|c|c|c|c|c|c|}
\hline $\begin{array}{l}\text { First Author } \\
\text { (Year of } \\
\text { Publication) }\end{array}$ & $\begin{array}{l}\text { Study } \\
\text { Design }\end{array}$ & $\begin{array}{l}\text { Sample Size } \\
(\mathrm{M} / \mathrm{F})\end{array}$ & $\begin{array}{l}\text { Exercise } \\
\text { Mode }\end{array}$ & $\begin{array}{c}\text { Intervention } \\
\text { Duration }\end{array}$ & $\begin{array}{c}\text { Session } \\
\text { Frequency }\end{array}$ & $\begin{array}{l}\text { Exercise } \\
\text { Intensity } \\
\text { (Category) }\end{array}$ & $\begin{array}{l}\text { Technique } \\
\text { used for } \\
\text { Assessment } \\
\text { of IHTG }\end{array}$ & $\begin{array}{l}\text { Index of } \\
\text { Basal } \\
\text { Hepatic IS } \\
\text { Originally } \\
\text { Reported }\end{array}$ & $\begin{array}{l}\text { Details of Low- } \\
\text { Dose Insulin } \\
\text { Infusion }\end{array}$ & $\begin{array}{c}\text { Weight } \\
\text { Change with } \\
\text { Exercise } \\
\text { Training } \\
\text { (mean \% } \\
\text { change from } \\
\text { baseline) }\end{array}$ \\
\hline $\begin{array}{l}\text { Cassidy } \\
(2016)\end{array}$ & RCT & $\begin{array}{l}\text { Ex: } 12(10 / 2) \\
\text { Con: } 11(8 / 3)\end{array}$ & HIIT & 12 weeks & $\begin{array}{l}3 \text { times per } \\
\text { week }\end{array}$ & High & ${ }^{1} \mathrm{H}-\mathrm{MRS}$ & - & - & $-1.1^{\beta}$ \\
\hline $\begin{array}{l}\text { Cuthbertson } \\
(2016)\end{array}$ & RCT & $\begin{array}{l}\text { Ex: } 30(23 / 7) \\
{[12(8 / 3 / 1 \mathrm{NR})]} \\
\text { Con: } 20(16 / 4) \\
{[7(3 / 4)]}\end{array}$ & Aerobic & 12 weeks & $\begin{array}{l}3-5 \text { times } \\
\text { per week }\end{array}$ & Moderate & ${ }^{1} \mathrm{H}-\mathrm{MRS}$ & HIRI & $\begin{array}{l}0.3 \mathrm{mU} \cdot \mathrm{kg}^{-1} \cdot \mathrm{min}^{-1} \\
\quad \text { for } 120 \mathrm{~min}\end{array}$ & $-2.5^{\alpha, \beta}$ \\
\hline $\begin{array}{l}\text { Hallsworth } \\
\text { (2011) }\end{array}$ & $\mathrm{RCT}$ & $\begin{array}{l}\text { Ex: } 11 \text { (NR) } \\
\text { Con: } 8 \text { (NR) }\end{array}$ & Resistance & 8 weeks & $\begin{array}{l}3 \text { times per } \\
\text { week }\end{array}$ & N/A & ${ }^{1} \mathrm{H}-\mathrm{MRS}$ & - & - & 0.0 \\
\hline $\begin{array}{l}\text { Hallsworth } \\
(2015)\end{array}$ & RCT & $\begin{array}{l}\text { Ex: } 12(6 / 6) \\
\text { Con: } 11(10 / 1)\end{array}$ & HIIT & 12 weeks & $\begin{array}{l}3 \text { times per } \\
\text { week }\end{array}$ & High & ${ }^{1} \mathrm{H}-\mathrm{MRS}$ & - & - & $-1.6^{\alpha, \beta}$ \\
\hline $\begin{array}{l}\text { Haus } \\
(2013)\end{array}$ & $\begin{array}{l}\text { Uncontrolled } \\
\text { Intervention }\end{array}$ & Ex: 17 (NR) & Aerobic & 1 week & $\begin{array}{l}7 \text { times per } \\
\text { week }\end{array}$ & High & ${ }^{1} \mathrm{H}-\mathrm{MRS}$ & - & - & 0.2 \\
\hline $\begin{array}{l}\text { Hickman } \\
(2013)\end{array}$ & $\mathrm{RCT}^{*}$ & $\begin{array}{l}\text { Ex: } 9(7 / 2) \\
{[13(9 / 4)]}\end{array}$ & Resistance & 24 weeks & $\begin{array}{l}3 \text { times per } \\
\text { week }\end{array}$ & N/A & Biopsy $^{\dagger}$ & HIRI & - & -2.6 \\
\hline $\begin{array}{l}\text { Houghton } \\
\text { (2017) }\end{array}$ & RCT & $\begin{array}{l}\text { Ex: } 12(7 / 5) \\
\text { Con: } 12(7 / 5)\end{array}$ & $\begin{array}{l}\text { Combined } \\
\text { (HIIT + } \\
\text { Resistance) }\end{array}$ & 12 weeks & $\begin{array}{l}3 \text { times per } \\
\text { week }\end{array}$ & High & ${ }^{1} \mathrm{H}-\mathrm{MRS}$ & - & - & 1.1 \\
\hline
\end{tabular}


Page 36 of $\mathbf{4 3}$

\begin{tabular}{|c|c|c|c|c|c|c|c|c|c|c|}
\hline $\begin{array}{l}\text { Johnson } \\
\text { (2009) }\end{array}$ & RCT & $\begin{array}{l}\text { Ex: } 12 \text { (NR) } \\
\text { Con: } 7 \text { (NR) }\end{array}$ & Aerobic & 4 weeks & $\begin{array}{l}3 \text { times per } \\
\text { week }\end{array}$ & Moderate & ${ }^{1} \mathrm{H}-\mathrm{MRS}$ & - & - & -0.3 \\
\hline $\begin{array}{l}\text { Keating } \\
(2015)\end{array}$ & $\mathrm{RCT}$ & $\begin{array}{l}\text { Ex1: } 12(6 / 6) \\
\text { Ex2: } 11(5 / 6) \\
\text { Con: } 12(3 / 9)\end{array}$ & Aerobic & 8 weeks & $\begin{array}{l}\text { Ex1: } 3 \\
\text { sessions per } \\
\text { week } \\
\text { Ex2: } 4 \\
\text { sessions per } \\
\text { week }\end{array}$ & $\begin{array}{l}\text { Ex1: High } \\
\text { Ex2: Moderate }\end{array}$ & ${ }^{1} \mathrm{H}-\mathrm{MRS}$ & - & - & $\begin{array}{l}\text { Ex1: }-1.2^{\alpha, \beta} \\
\text { Ex2: }-1.5^{\alpha, \beta}\end{array}$ \\
\hline $\begin{array}{l}\text { Langleite } \\
\text { (2016) }\end{array}$ & $\begin{array}{l}\text { Uncontrolled } \\
\text { Intervention }\end{array}$ & Ex: $11(11 / 0)$ & $\begin{array}{l}\text { Combined } \\
\text { (Aerobic }+ \\
\text { HIIT }+ \\
\text { Resistance) }\end{array}$ & 12 weeks & $\begin{array}{l}4 \text { times per } \\
\text { week } \\
(1 \text { aerobic, } \\
1 \text { HIIT, } 2 \\
\text { resistance })\end{array}$ & High & ${ }^{1} \mathrm{H}-\mathrm{MRS}$ & - & - & -1.2 \\
\hline $\begin{array}{l}\text { Lee } \\
(2013)\end{array}$ & RCT & $\begin{array}{l}\text { Ex1: }[16(0 / 16)] \\
\text { Ex2: }[16(0 / 16)] \\
\text { Con: }[12(0 / 12)]\end{array}$ & $\begin{array}{l}\text { Ex1: } \\
\text { Aerobic } \\
\text { Ex2: } \\
\text { Resistance }\end{array}$ & 12 weeks & $\begin{array}{l}3 \text { times per } \\
\text { week }\end{array}$ & High & - & $\mathrm{HISI}^{\dagger}$ & - & $\begin{array}{l}\text { Ex1: }-1.3 \\
\text { Ex2: }-0.3\end{array}$ \\
\hline $\begin{array}{l}\text { Malin } \\
(2013)\end{array}$ & $\begin{array}{l}\text { Uncontrolled } \\
\text { Intervention }\end{array}$ & Ex: $13(6 / 7)$ & Aerobic & 1 week & $\begin{array}{l}7 \text { times per } \\
\text { week }\end{array}$ & High & ${ }^{1} \mathrm{H}-\mathrm{MRS}$ & - & - & 0.6 \\
\hline $\begin{array}{l}\text { Meex } \\
(2010)\end{array}$ & $\begin{array}{l}\text { Uncontrolled } \\
\text { Intervention }\end{array}$ & $\begin{array}{l}\text { Ex1: }[20(20 / 0)] \\
\text { Ex2: }[17(17 / 0)]\end{array}$ & $\begin{array}{l}\text { Combined } \\
(\text { Aerobic }+ \\
\text { Resistance) }\end{array}$ & 12 weeks & $\begin{array}{l}3 \text { times per } \\
\text { week } \\
\text { ( } 2 \text { aerobic, } 1 \\
\text { resistance) }\end{array}$ & Moderate & - & HISI $^{\#}$ & - & $\begin{array}{l}\text { Ex1: }-1.1 \\
\text { Ex2: }-1.0\end{array}$ \\
\hline $\begin{array}{l}\text { Oh } \\
(2014)\end{array}$ & $\begin{array}{l}\text { Uncontrolled } \\
\text { Intervention }\end{array}$ & Ex: $18(4 / 14)$ & $\begin{array}{l}\text { Vibration / } \\
\text { Acceleration }\end{array}$ & 6 weeks & $\begin{array}{l}3 \text { times per } \\
\text { week }\end{array}$ & N/A & ${ }^{1} \mathrm{H}-\mathrm{MRS}$ & - & - & $-0.4^{\alpha}$ \\
\hline $\begin{array}{l}\text { Pugh } \\
(2014)\end{array}$ & $\mathrm{RCT}$ & $\begin{array}{l}\text { Ex: } 13(7 / 6) \\
\text { Con: } 8(4 / 4)\end{array}$ & Aerobic & 16 weeks & $\begin{array}{l}3-5 \text { times } \\
\text { per week }\end{array}$ & Moderate & ${ }^{1} \mathrm{H}-\mathrm{MRS}$ & - & - & -2.4 \\
\hline $\begin{array}{l}\text { Sargeant } \\
(2018)\end{array}$ & $\begin{array}{l}\text { Controlled } \\
\text { Longitudinal } \\
\text { Intervention }\end{array}$ & $\begin{array}{l}\text { Ex: } 9(9 / 0) \\
{[8(8 / 0)]}\end{array}$ & HIIT & 6 weeks & $\begin{array}{l}3 \text { times per } \\
\text { week }\end{array}$ & High & ${ }^{1} \mathrm{H}-\mathrm{MRS}$ & HISI & $\begin{array}{l}20 \mathrm{mU} \cdot \mathrm{m}^{-2} \cdot \mathrm{min}^{-1} \\
\text { for } 120 \mathrm{~min}\end{array}$ & -1.2 \\
\hline
\end{tabular}


Page 37 of 43

\begin{tabular}{|c|c|c|c|c|c|c|c|c|c|c|}
\hline $\begin{array}{l}\text { Shojaee- } \\
\text { Moradie } \\
(2007)\end{array}$ & $\mathrm{RCT}$ & $\begin{array}{l}\text { Ex: [10 (10/0)] } \\
\text { Con: }[7(7 / 0)]\end{array}$ & Aerobic & 6 weeks & $\begin{array}{l}3 \text { times per } \\
\text { week }\end{array}$ & High & - & $\mathrm{HISI}^{*}$ & $\begin{array}{l}0.3 \mathrm{mU} \cdot \mathrm{kg}^{-1} \cdot \mathrm{min}^{-1} \\
\quad \text { for } 120 \mathrm{~min}\end{array}$ & -0.8 \\
\hline $\begin{array}{l}\text { Sullivan } \\
(2012)\end{array}$ & RCT & $\begin{array}{l}\text { Ex: } 12(4 / 8) \\
\text { Con: } 6(1 / 5)\end{array}$ & Aerobic & 16 weeks & $\begin{array}{l}5 \text { times per } \\
\text { week }\end{array}$ & Moderate & ${ }^{1} \mathrm{H}-\mathrm{MRS}$ & - & - & $-0.2^{\alpha}$ \\
\hline $\begin{array}{l}\text { van der } \\
\text { Heijden } \\
(2010 a)^{\sharp}\end{array}$ & $\begin{array}{l}\text { Uncontrolled } \\
\text { Intervention }\end{array}$ & $\begin{array}{l}\text { Ex: } 15(7 / 8) \\
{[15(7 / 8)]}\end{array}$ & Aerobic & 12 weeks & $\begin{array}{l}4 \text { times per } \\
\text { week }\end{array}$ & High & ${ }^{1} \mathrm{H}-\mathrm{MRS}$ & HISI & - & -0.5 \\
\hline $\begin{array}{l}\text { van der } \\
\text { Heijden } \\
(2010 b)\end{array}$ & $\begin{array}{l}\text { Uncontrolled } \\
\text { Intervention }\end{array}$ & $\begin{array}{l}\text { Ex: } 7(\mathrm{NR}) \\
{[12(6 / 6)]}\end{array}$ & Resistance & 12 weeks & $\begin{array}{l}2 \text { times per } \\
\text { week }\end{array}$ & N/A & ${ }^{1} \mathrm{H}-\mathrm{MRS}$ & HISI & - & $2.6^{\alpha}$ \\
\hline $\begin{array}{l}\text { Zhang } \\
\text { (2016) }\end{array}$ & RCT & $\begin{array}{l}\text { Ex1: } 73(22 / 51) \\
\text { Ex2: } 73(21 / 52) \\
\text { Con: } 74(28 / 46)\end{array}$ & Aerobic & 24 weeks & $\begin{array}{l}5 \text { times per } \\
\text { week }\end{array}$ & $\begin{array}{l}\text { Ex1: Moderate } \\
\text { Ex2: High }\end{array}$ & ${ }^{1} \mathrm{H}-\mathrm{MRS}$ & - & - & $\begin{array}{l}\text { Ex1: }-2.8^{\alpha, \beta} \\
\text { Ex2: }-6.0^{\alpha \beta}\end{array}$ \\
\hline
\end{tabular}




\section{Table \& Figure Legends}

Table 1 - Categories of exercise intensity. Adapted from (31); \% HR max: percentage of maximal heart rate; $\% \mathrm{HRR}$ : percentage of heart rate reserve; $\% \dot{V} \mathrm{O}_{2}$ peak: percentage of peak oxygen uptake; RPE: rating of perceived exertion (69).

Table 2 - Overview of included studies. Sample sizes in squared brackets represent the number of participants included in hepatic insulin sensitivity outcomes; Mean changes in body weight with exercise are as reported in the original manuscript $\left({ }^{\alpha}\right.$ indicates significantly different from baseline, ${ }^{\beta}$ indicates significantly different from non-exercise control group); Exercise intensity is categorised according to published criteria (31), which are summarised in Table 1; *Study did not include a 'standard care' or 'no intervention' group, exercise was compared with hypocaloric diet; ${ }^{\dagger}$ Study was excluded from one or more meta-analyses Hickman et al (2013) was removed from meta-analyses of changes in hepatic steatosis to reduce heterogeneity as it was the only study using liver biopsy to assess IHTG. Lee et al (2013) was removed from meta-analysis of changes in basal hepatic insulin sensitivity because raw data were not available to allow re-calculation of HISI as outlined by Matsuda and DeFronzo (1999); "Published manuscript contained no index of hepatic insulin sensitivity. HISI was calculated after authors provided raw data; ${ }^{*}$ Manuscript refers to the same study as van der Heijden et al (2009); ${ }^{1} \mathrm{H}-\mathrm{MRS}$ : Proton magnetic resonance spectroscopy; Con: Control group; Ex1/2: Exercise group 1/2; HISI: hepatic insulin sensitivity index; IHTG: intrahepatic triglyceride; N/A: not applicable; NR: not reported; RCT: randomised controlled

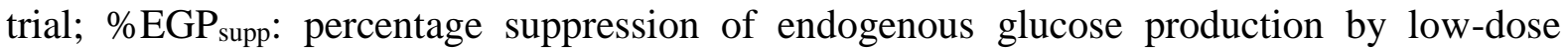
insulin infusion. 
Figure 1 - Flowchart of literature search process. An overview of the literature search and study selection process.

Figure 2 - Meta-analysis of the pooled effect of exercise training on IHTG from pre- to post-training in all exercise groups of all eligible studies. Studies are grouped by exercise mode. IHTG: intrahepatic triglyceride; 95\% CI: 95\% confidence interval; HIIT: highintensity interval training; Combined: combined aerobic- or HIIT-plus-resistance exercise training.

Figure 3 - Meta-analysis of the pooled effect of exercise training on IHTG from pre- to post-training in all exercise groups of all eligible studies when studies are grouped into those that elicited weight loss versus those that did not. IHTG: intrahepatic triglyceride; 95\% CI: 95\% confidence interval.

Figure 4 - Meta-analysis of the pooled effect of exercise training on HISI from pre- to post-training in all exercise groups of all eligible studies. HISI: hepatic insulin sensitivity index; 95\% CI: 95\% confidence interval; Combined: combined aerobic-plus-resistance exercise training; HIIT: high-intensity interval training. 
Figure 1

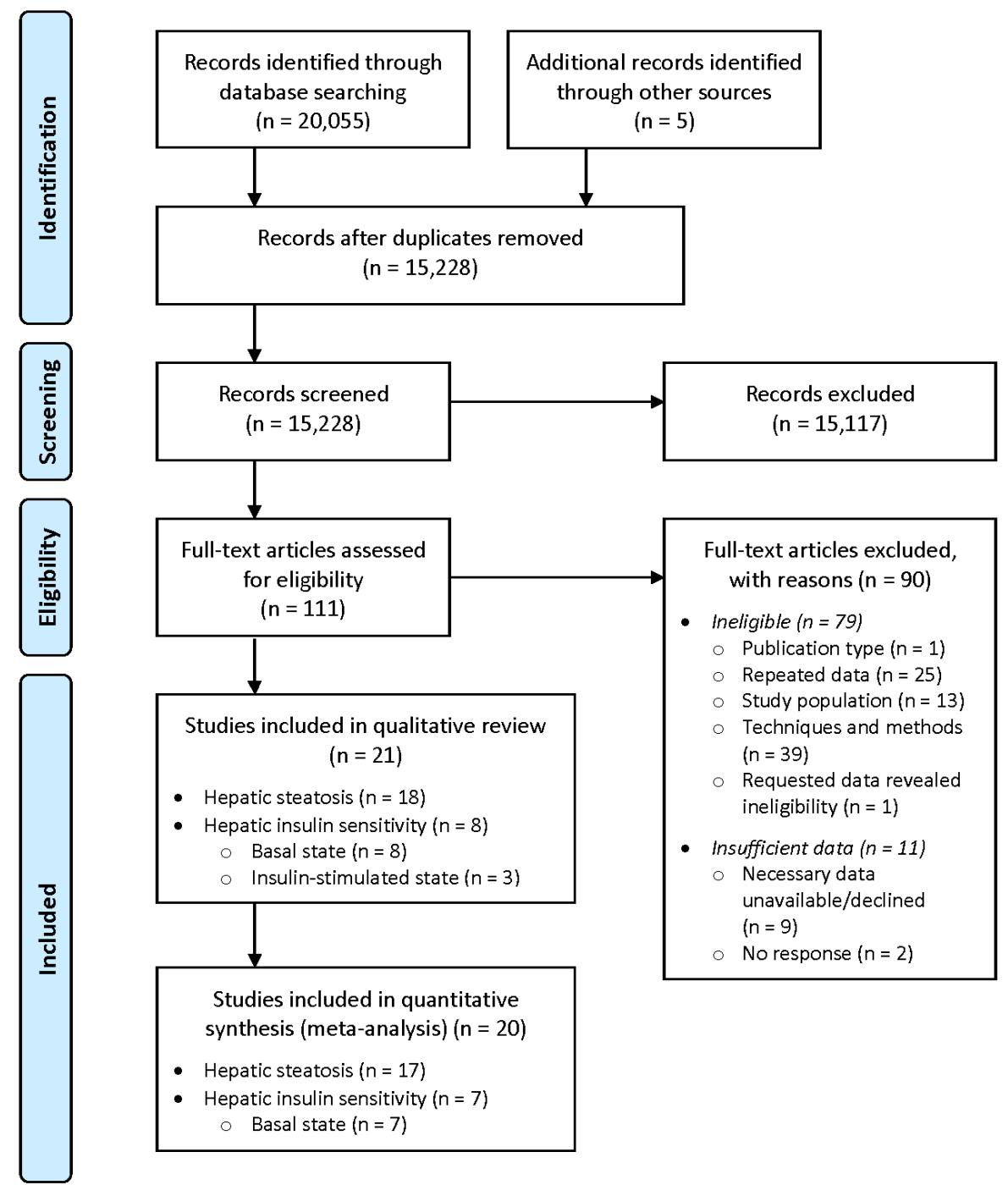


Page 41 of 43

\section{Figure 2}

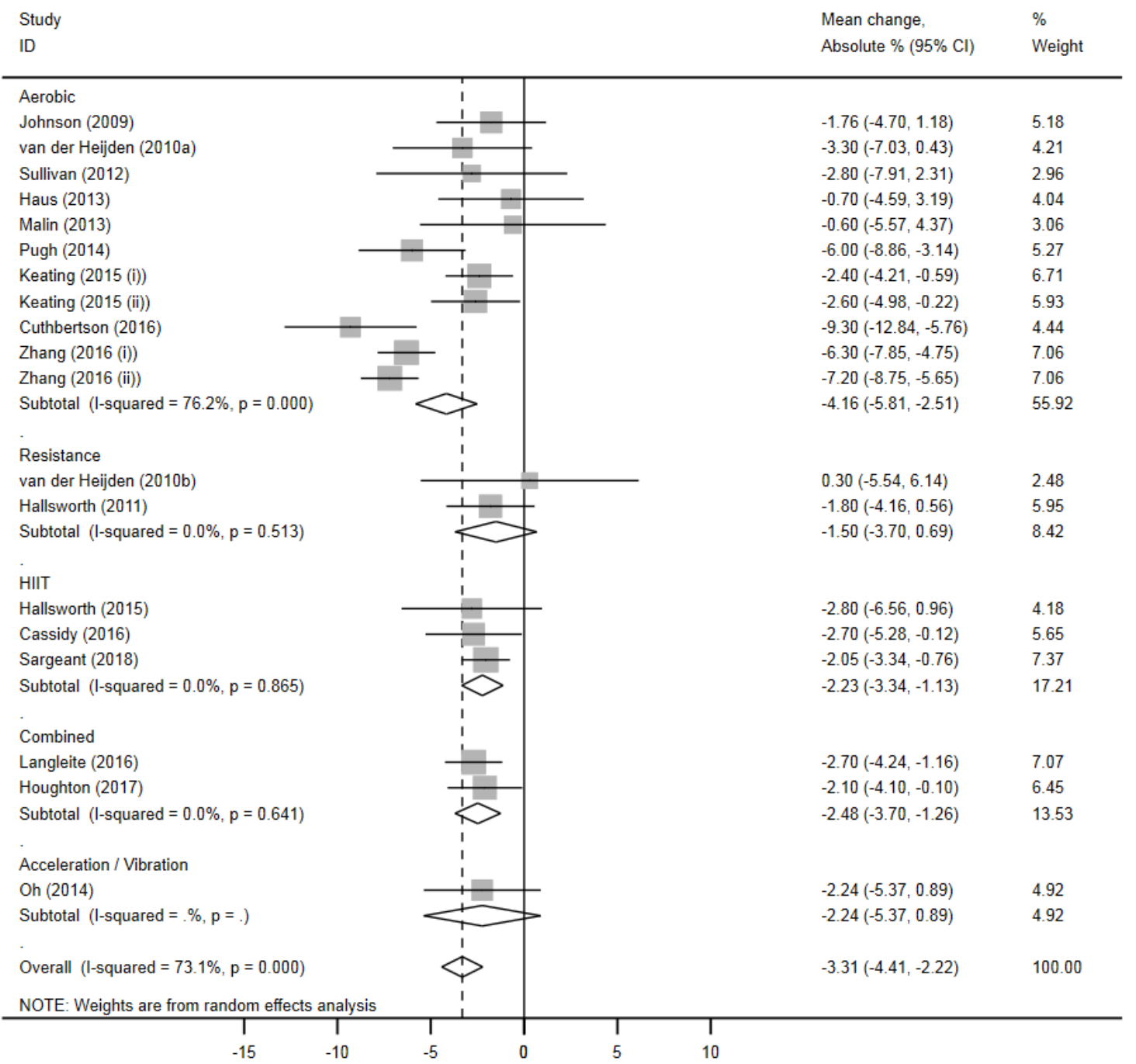


Figure 3

Study

ID

No significant weight loss reported

Johnson (2008)

van der Heijden (2010a)

van der Heijden (2010b)

Hallsworth (2011)

Sullivan (2012)

Haus (2013)

Malin (2013)

Cassidy (2016)

Langleite (2016)

Houghton (2017)

Sargeant (2018)

Subtotal (1-5quared $=0.0 \%, p=0.085$ )

Significant weight loss reported

On (2014)

Pugh (2014)

Hallsworth (2015)

Keating (2015 (i))

Keating (2015 (ii))

Cuthbertson (2018)

Zhang (2016 (i))

Zhang (2016 (ii))

Subtotal (1-squared $=78.5 \%, p=0.000$ )

Overall (1-squared $=73.1 \%, p=0.000$ )

NOTE: Weights are from random effects analysis

$\begin{array}{ll}\text { Absolute } & \% \\ \text { change, } \%(05 \% \mathrm{Cl}) & \text { Weight }\end{array}$

$-1.78(-4.70,1.18) \quad 5.18$

$-3.30(-7.03,0.43) \quad 4.21$

$0.30(-5.54,8.14) \quad 2.48$

$-1.80(-4.18,0.56) \quad 5.95$

$-2.80(-7.91,2.31) \quad 2.96$

$-0.70(-4.59,3.19) \quad 4.04$

$-0.80(-5.57,4.37) \quad 3.06$

$-2.70(-5.28,-0.12) \quad 5.65$

$-2.70(-4.24,-1.16) \quad 7.07$

$-2.10(-4.10,-0.10) \quad 6.45$

$-2.05(-3.34,-0.76) \quad 7.37$

$-2.18(-2.87,-1.44) \quad 54.43$

$-2.24(-5.37,0.88) \quad 4.92$

$-6.00(-8.86,-3.14) \quad 5.27$

$-2.80(-8.56,0.08) \quad 4.18$

$-2.40(-4.21,-0.58) \quad 6.71$

$-2.80(-4.98,-0.22) \quad 5.93$

$-9.30(-12.84,-5.76) \quad 4.44$

$-6.30(-7.85,-4.75) \quad 7.06$

$\begin{aligned}-7.20(-8.75,-5.65) & 7.06\end{aligned}$

$-4.87(-6.84,-3.11) \quad 45.57$

$-3.31(-4.41,-2.22) \quad 100.00$ 
Page 43 of 43

Figure 4

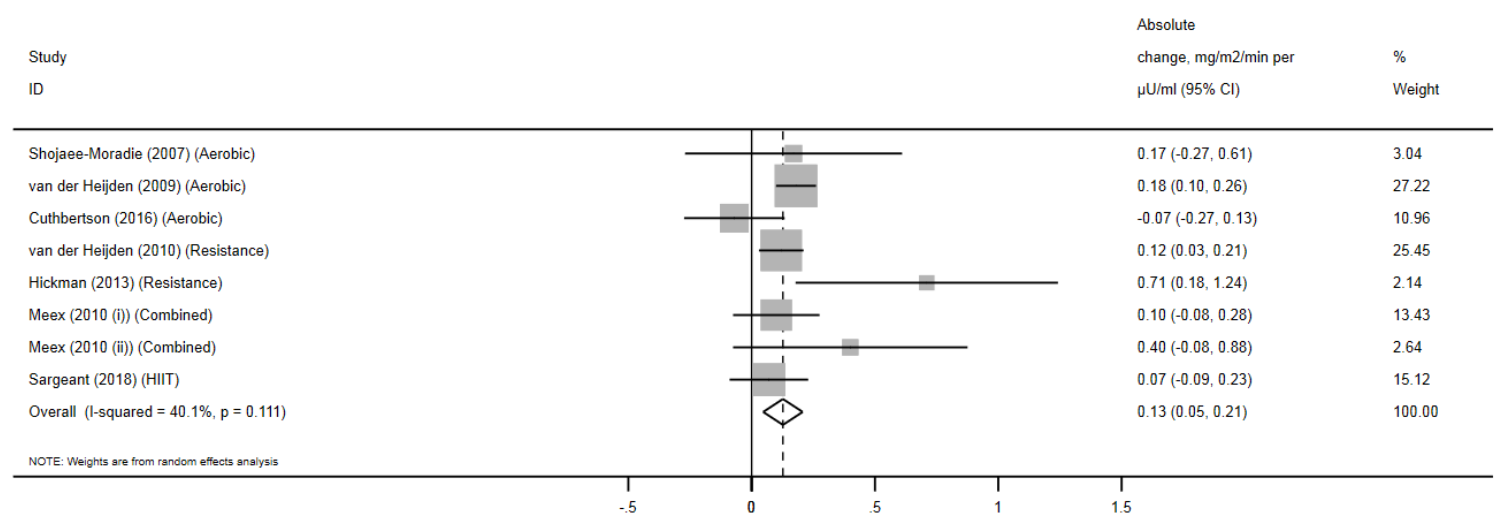

